\title{
Supramolecular architecture in an Oxovanadium(V)-Schiff base complex: Synthesis, Ab-initio structure determination from X-ray powder diffraction, DNA binding and cleavage activity.
}

Swastik Mondal, ${ }^{a}$ Monika Mukherjee, ${ }^{* a}$ Koushik Dhara, ${ }^{b}$ Soumen Ghosh, ${ }^{c}$

Jagnyeswar Ratha, ${ }^{d}$ Pradyot Banerjee ${ }^{b}$ and Alok K. Mukherjee ${ }^{c}$

Atomic Coordinates of $\left[\left(\mathrm{VO}_{2}\right)_{2}\left(\mathrm{C}_{12} \mathrm{H}_{17} \mathrm{~N}_{2} \mathrm{O}\right)_{2}\right]$ from Rietveld analysis:

$\begin{array}{llll}\mathrm{V} 1 & 0.5125(14) & 0.8746(6) & -0.0089(8) \\ \mathrm{O} 1 & 0.356(3) & 0.756(2) & 0.016(1) \\ \mathrm{O} 2 & 0.341(3) & 0.961(2) & -0.020(2) \\ \mathrm{O} 3 & 0.520(5) & 0.871(3) & -0.125(1) \\ \mathrm{N} 1 & 0.536(4) & 0.880(3) & 0.148(1) \\ \mathrm{N} 2 & 0.740(3) & 0.786(2) & 0.031(2) \\ \mathrm{C} 1 & 0.294(3) & 0.709(2) & 0.095(1) \\ \mathrm{C} 2 & 0.221(3) & 0.603(2) & 0.086(2) \\ \mathrm{C} 3 & 0.152(3) & 0.551(2) & 0.167(2) \\ \mathrm{C} 4 & 0.156(3) & 0.604(2) & 0.256(2) \\ \mathrm{C} 5 & 0.229(3) & 0.710(2) & 0.265(1) \\ \mathrm{C} 6 & 0.298(3) & 0.762(2) & 0.184(2) \\ \mathrm{C} 7 & 0.394(4) & 0.862(2) & 0.192(2) \\ \mathrm{C} 8 & 0.679(4) & 0.829(4) & 0.204(2) \\ \mathrm{C} 9 & 0.815(4) & 0.802(4) & 0.132(2) \\ \mathrm{C} 10 & 0.366(5) & 0.936(4) & 0.276(2) \\ \mathrm{C} 11 & 0.748(6) & 0.664(3) & 0.025(4) \\ \mathrm{C} 12 & 0.860(3) & 0.829(3) & -0.043(2)\end{array}$


Crystallographic data for $\left[\left\{\mathrm{VO}_{2}\left(\mathrm{C}_{12} \mathrm{H}_{17} \mathrm{~N}_{2} \mathrm{O}\right)\right\}_{2}\right]$.

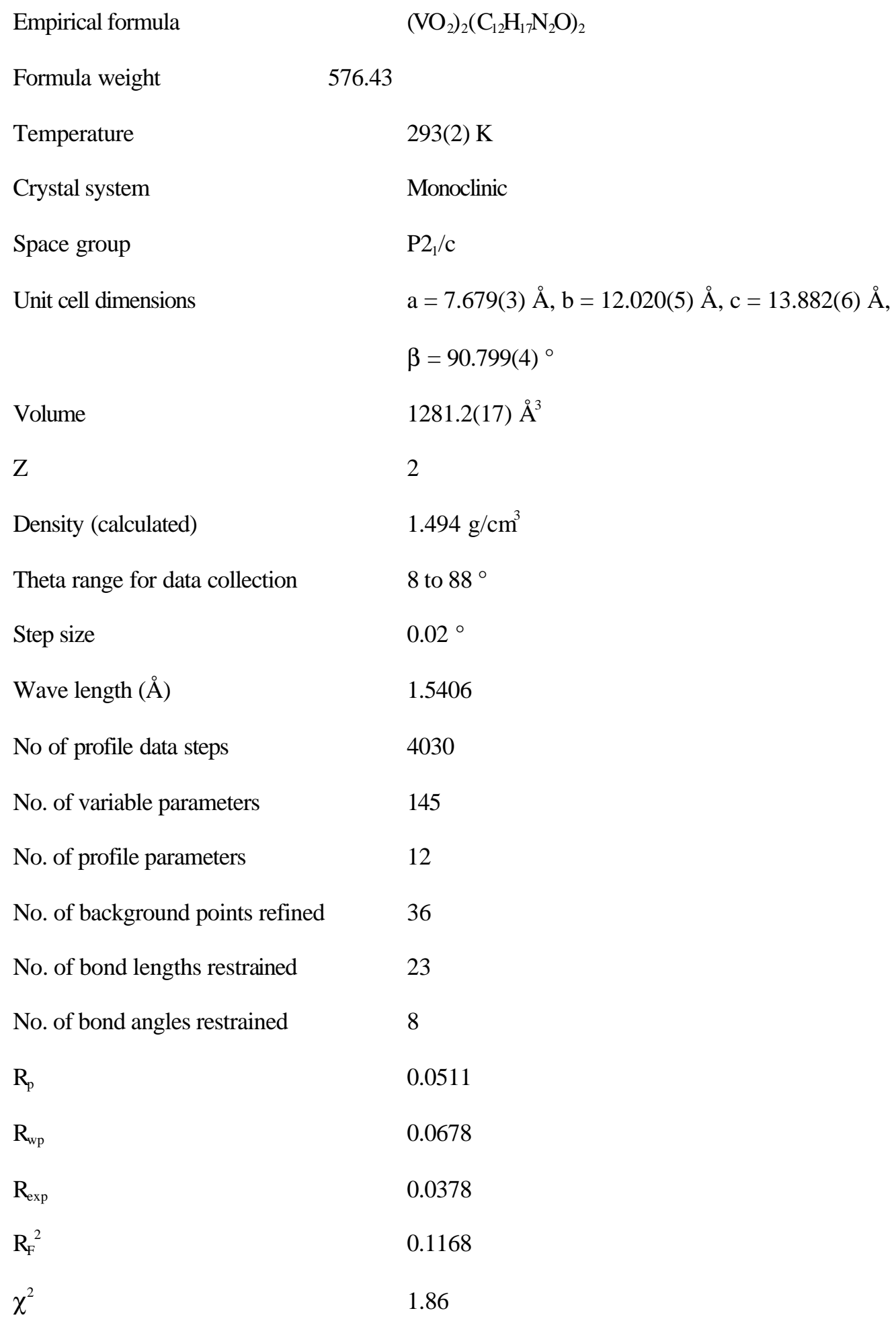


Selected Bond lengths $(\AA)$ and Bond angles $\left(^{\circ}\right)$

\begin{tabular}{|c|c|c|c|}
\hline atoms & bond length $(\AA)$ & atoms & bond length $(\AA)$ \\
\hline $\mathrm{V} 1-\mathrm{V} 1^{\mathrm{i}}$ & $3.030(14)$ & V1-N1 & $2.180(2)$ \\
\hline V1-O1 & $1.900(2)$ & V1-N2 & $2.110(2)$ \\
\hline $\mathrm{V} 1-\mathrm{O} 2$ & $1.680(2)$ & N1-C8 & $1.470(2)$ \\
\hline $\mathrm{V} 1-\mathrm{O} 2^{\mathrm{i}}$ & $2.310(2)$ & C8-C9 & $1.500(2)$ \\
\hline V1-O3 & $1.610(2)$ & N2- C9 & $1.520(2)$ \\
\hline atoms & bond angle $\left(^{\circ}\right)$ & atoms & bond angle $\left(^{\circ}\right)$ \\
\hline $\mathrm{O} 1-\mathrm{V} 1-\mathrm{O} 2$ & $9.1(13)$ & $\mathrm{O} 2-\mathrm{V} 1-\mathrm{O} 3$ & $87.8(18)$ \\
\hline $\mathrm{O} 1-\mathrm{V} 1-\mathrm{O} 2 \mathrm{i}$ & $57.0(12)$ & $\mathrm{O} 2-\mathrm{V} 1-\mathrm{N} 1$ & $97.5(15)$ \\
\hline O1-V1-O3 & $101.2(15)$ & $\mathrm{O} 2-\mathrm{V} 1-\mathrm{N} 2$ & $168.2(14)$ \\
\hline O1-V1-N1 & $83.5(14)$ & $\mathrm{O} 2-\mathrm{V} 1-\mathrm{O} 2 \mathrm{i}$ & $82.4(10)$ \\
\hline O1-V1-N2 & $95.5(11)$ & $\mathrm{O} 2 \mathrm{i}-\mathrm{V} 1-\mathrm{O} 3$ & $99.8(16)$ \\
\hline $\mathrm{O} 2 \mathrm{i}-\mathrm{V} 1-\mathrm{N} 1$ & $76.6(12)$ & $\mathrm{O} 2 \mathrm{i}-\mathrm{V} 1-\mathrm{N} 2$ & $89.3(11)$ \\
\hline O3-V1-N1 & 173.0(18) & O3-V1-N2 & 101.9(17) \\
\hline N1-V1-N2 & $72.3(11)$ & $\mathrm{V} 1-\mathrm{O} 2-\mathrm{V} 1^{\mathrm{i}}$ & $97.6(10)$ \\
\hline
\end{tabular}

Symmetry code: (i) 1-x, 2-y, -z 


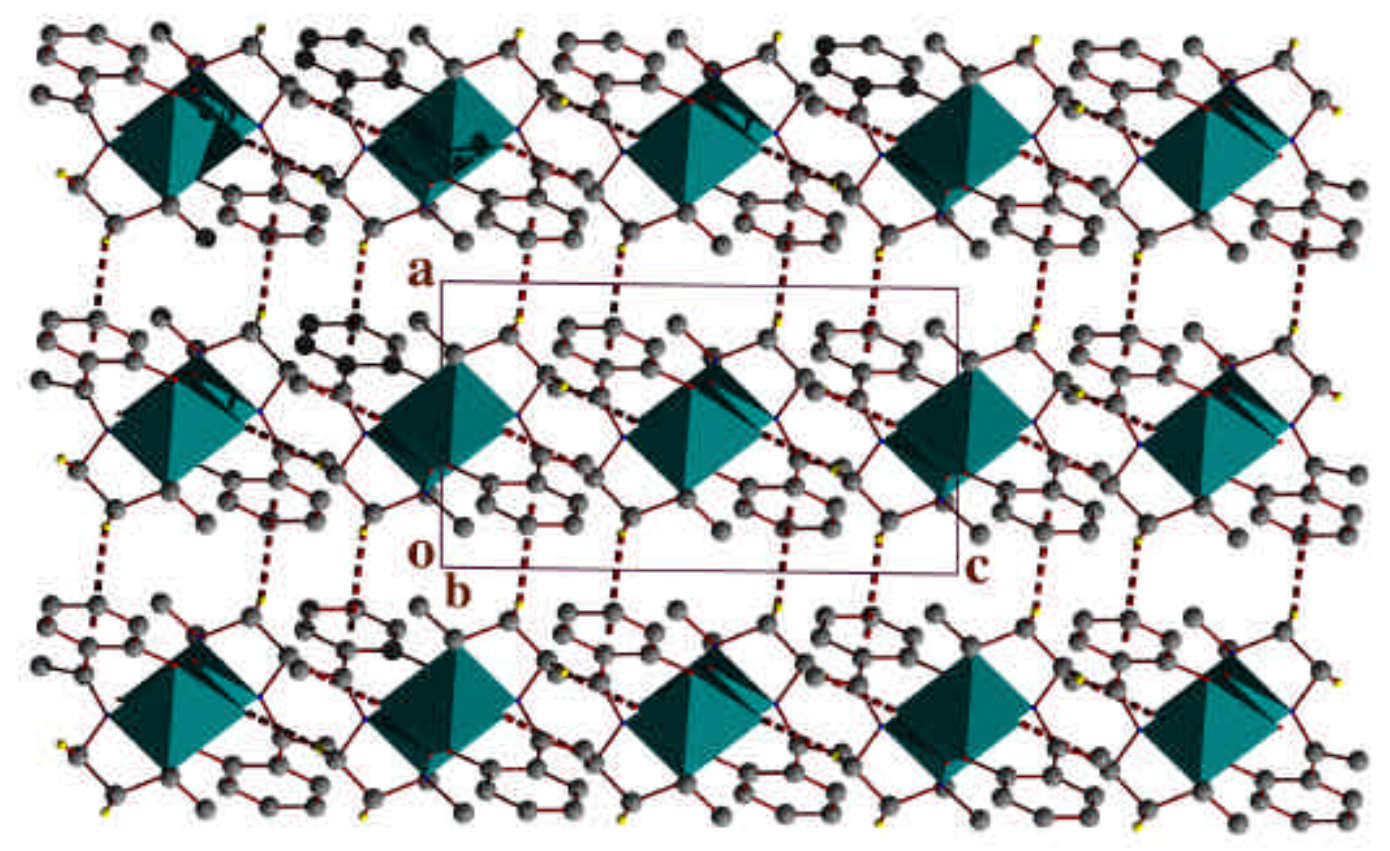

Molecular packing of $\left[\left(\mathrm{VO}_{2}\right)_{2}\left(\mathrm{C}_{12} \mathrm{H}_{17} \mathrm{~N}_{2} \mathrm{O}\right)_{2}\right]$ viewed along [010] direction.

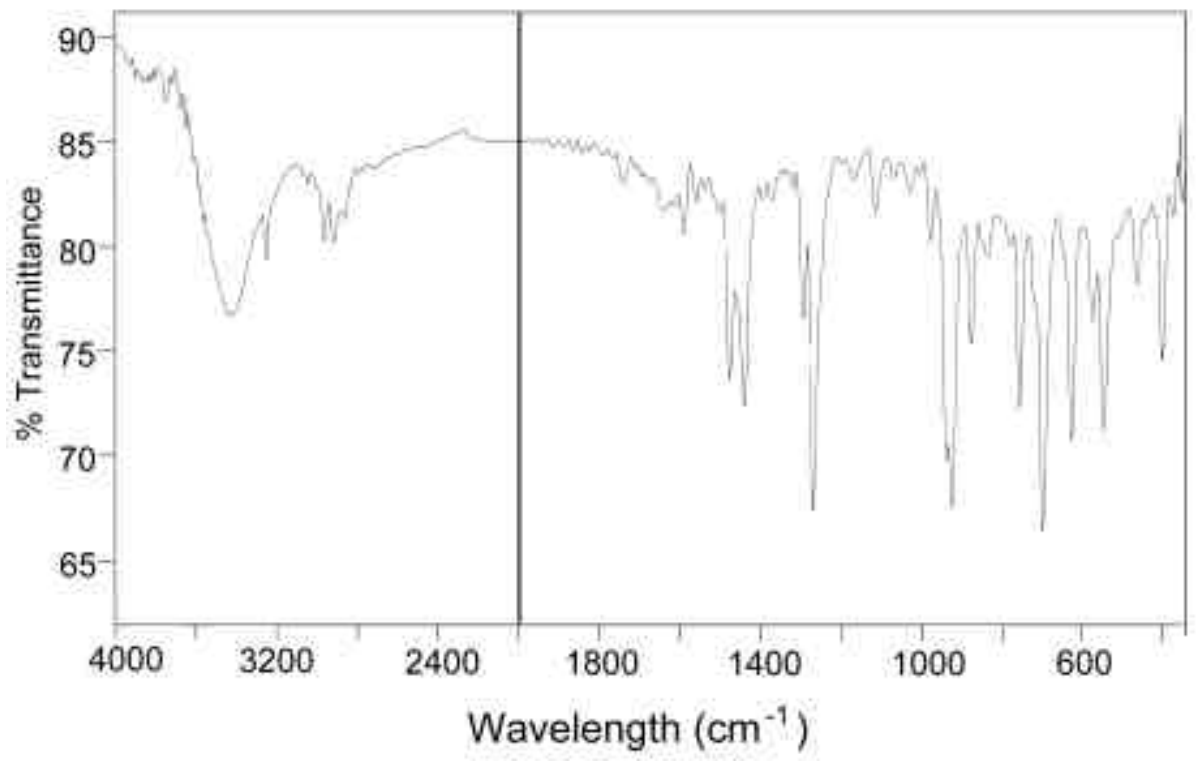

Figure S1. FTIR Spectra of $\left[\left(\mathrm{VO}_{2}\right)_{2}\left(\mathrm{C}_{12} \mathrm{H}_{17} \mathrm{~N}_{2} \mathrm{O}\right)_{2}\right]$ 


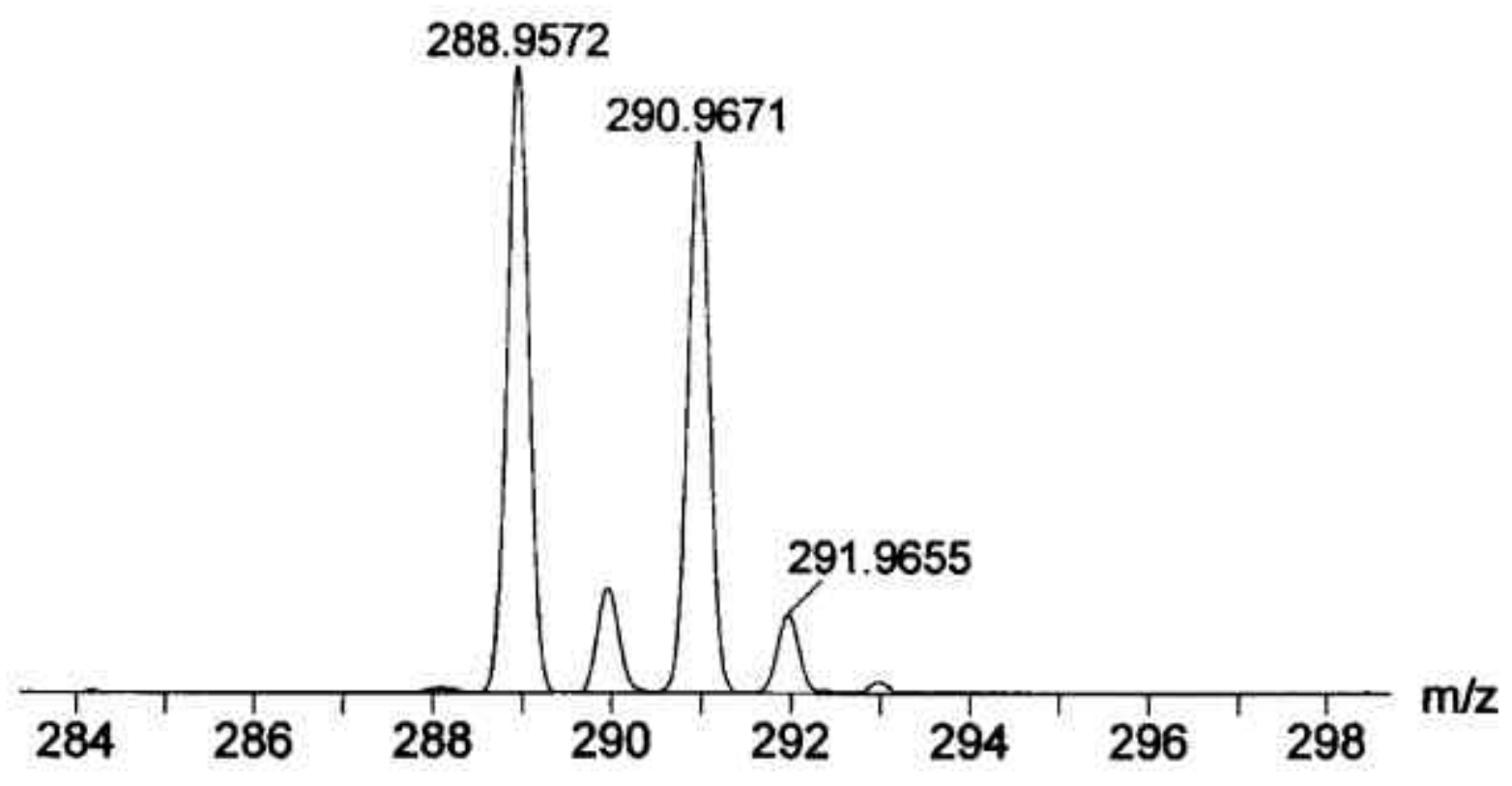

Figure S2. Electronspray mass spectra of $\mathbf{1}$ shows peak at 288.9 that can be assigned to the $\left[\mathrm{M}+\mathrm{H}^{+}\right]^{+}$where $\mathrm{M}=\left[\left(\mathrm{VO}_{2}\right)\left(\mathrm{C}_{12} \mathrm{H}_{17} \mathrm{~N}_{2} \mathrm{O}\right)\right]$ 